\title{
Analysis of Fracture Behavior of Large Steel Beam-Column Connections
}

\author{
Liangjie Qi ${ }^{\mathrm{a}}$, Jonathan Paquette ${ }^{\mathrm{b}}$, Matthew Eatherton ${ }^{\mathrm{b}}$, Roberto Leon ${ }^{\mathrm{b} *}$, Teodora \\ Bogdan $^{c}$, Nicoleta Popa ${ }^{c}$ and Edurne Nunez Moreno ${ }^{d}$ \\ aDeparment of Civil Engineering, Xi' an University of Architecture and Technology, PRC \\ ${ }^{b}$ Via Department of Civil and Environmental Engineering, Virginia Tech, USA \\ ${ }^{c}$ ArcelorMittal Global Research and Development Esch, Luxenburg \\ ${ }^{\mathrm{d} A r c e l o r M i t t a l}$ Global Research and Development Basque Country, Spain \\ *corresponding author, e-mail address: rleon@vt.edu
}

\begin{abstract}
Recently completed experimental steel beam-column connection tests on the largest specimens of reduced-beam section specimens ever tested have shown that such connections can meet current seismic design qualification protocols, allowing to further extend the current AISC Seismic Provisions and the AISC Provisions for Prequalified Connections for Special and Intermediate Steel Moment Frames. However, the results indicate that geometrical and material effects need to be carefully considered when designing welded connections between very heavy shapes. Understanding of this behavior will ease the use of heavier structural shapes in seismic active areas of the United States, extending the use of heavy steel sections beyond their current use in ultra-tall buildings. To better interpret the experimental test results, extensive detailed finite element analyses are being conducted on the entire series of tests, which comprised four specimens with beams of four very different sizes. The analyses intend to clarify what scale effects, at both the material and geometric level, influence the performance of these connections. The emphasis is on modeling of the connection to understand the balance in deformation between the column panel zones and the reduced beam section, the stress concentrations near the welds, the effects of initial imperfections and residual stresses and the validity of several damage accumulation models. The models developed so far for all four specimens have been able to accurately reproduce the overall load-deformation and moment-rotation time histories.
\end{abstract}

Keywords: reduced beam sections; steel connections; welded connections; seismic design; connection modelling.

\section{Introduction}

The design of modern tall buildings, airport concourses, sports arenas and convention centers requires spanning long uninterrupted spaces, resulting in the need for members with very large load-carrying capacity. Amongst these are the largest steel sections currently being rolled, including sections as large as W920x1377 (W36x925) with steels of Grade65 or larger yield stresses. When the design is for areas of high seismicity, the design of welded connections for such large sections requires very carefully developed Welding Performance Specifications (WPS) to ensure that the required rotational capacities to reach interstory drifts of $4 \%$ can be developed.

One technique used to control the flexural demand from the beam is to utilize reduced beam sections (RBS), which effectively limit the demands at the beam-column interface (Figure 1). The RBS concept was proposed initially by Plumier [1] and used extensively in the SAC project [2] in the late 1990s to alleviate problems encountered in the 1994 Northridge Earthquake with conventional welded connections.

The current AISC Provisions for Steel Buildings (ANSI/AISC 360-16) [3], Seismic 
Provisions (ANSI/AISC 341-16) [4] and the Provisions for Prequalified Connections for Special and Intermediate Steel Moment Frames (ANSI-AISC 358-14) [5] allow the use of these connections but only for sections up to $900 \mathrm{~mm}$ in depth and $450 \mathrm{~kg} / \mathrm{m}$ in weight.

In order to extend the coverage of these specifications to much larger sections, a joint experimental and analytical program was undertaken by Virginia Tech and ArcelorMittal. This paper reports on the analytical studies undertaken before and after the tests to develop robust models that would allow for an extensive parametric study to simulate the behavior of these connections.

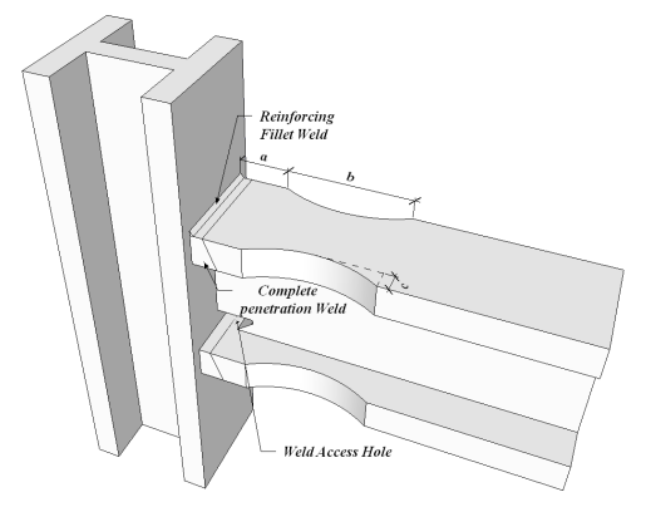

Fig. 1. RBS section connection

\section{Experimental Results}

As the intent was to extend the current limits of the AISC 358 provisions for RBS connections to beams with nominal depths up to $1100 \mathrm{~mm}$ and weights of up to $1377 \mathrm{~kg} / \mathrm{m}$, four specimens were designed and tested. Each specimen (see Table 1) was intended to provide a reasonable increase in either depth or weight.

The T-shapes specimens, similar to Figure 1, consisted of a $5 \mathrm{~m}$ column with a $5,5 \mathrm{~m}$ beam. The column ends were constrained to approximate a hinge, and the displacement was applied at the beam end. All beams were fabricated from A992 Grade 50 steel, all columns from A913 Grade 65 steel, and all doubler plates from A572 Grade 50 steel.

The experimental campaign was based on two efforts. The first effort was a series of trial designs to determine realistic members sizes in buildings in high seismicity areas. The study focused on a 15-story building in California with a large, open atrium in the first floor. This opening required a large transfer girder for which a section like the W920x420x1377 would be reasonable.

The second effort centered on determining a reasonable balance between the deformation obtained from flexural yielding of the RBS and shear yielding of the panel zone in the column. The desired failure mode for RBS connections is extensive yielding of the RBS and limited yielding of the panel zone, followed by inelastic local buckling of the beam in the RBS zone. Table 2 shows the slenderness parameters for the sections used, and it is clear that the web slenderness for SP2 $\left(\mathrm{h} / \mathrm{t}_{\mathrm{w}}=57.1\right)$ made this specimen especially susceptible to this failure mode shortly after yielding. The situation was slightly better for SP4 $\left(\mathrm{h} / \mathrm{t}_{\mathrm{w}}=33.2\right)$ where local buckling would be expected after considerable yielding.

For both SP1 and SP3, however, it is very unlikely that any local buckling would occur as the slenderness of both webs and flanges is very low, and the sections could be considered supercompact.

A design is deemed successful if the tested specimen reaches the second cycle at $4 \%$ of the prescribed AISC 358 displacement protocol (Table 3).

Development of the local buckling mechanism is important because it becomes a self-controlling limit on the hardening that will occur if only flexural yielding occurs. Figure 2 illustrates one of the early results using a relatively low-density FE mesh and nominal material properties. The figure illustrates the contribution of the four main mechanisms to the monotonic beam deformation: (a) beam elastic deformation, (b) column elastic deformation, (c) yielding in the RBS, and (d) panel zone yielding.

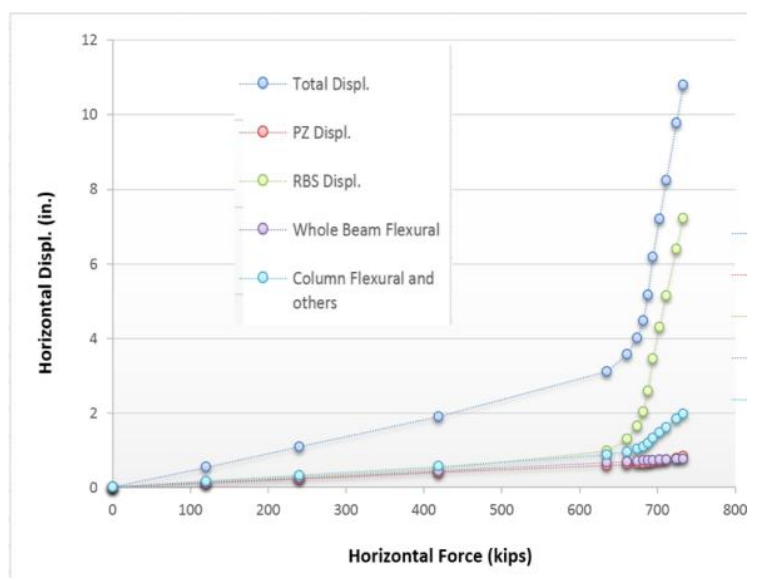

Fig. 2. Contributions to deformation for SP4 
Table 1 - Specimen details

\begin{tabular}{|c|c|c|c|c|}
\hline Specimen & Beam Section & Column Section & $\begin{array}{c}\text { Double } \\
\mathbf{r} \\
\text { Plates }\end{array}$ & $\begin{array}{l}\text { RBS } \\
\text { Cuts } \\
\text { (mm) }\end{array}$ \\
\hline SP1 & $\begin{array}{c}\text { W } 920 \times 420 \times 970 \\
(\text { W } 36 \times 652)\end{array}$ & $\begin{array}{c}\text { W } 360 \times 410 \times 1299 \\
(W 14 \times 873)\end{array}$ & None & $\begin{array}{l}a=335 \\
b=887 \\
c=80.5\end{array}$ \\
\hline SP2 & $\begin{array}{c}\mathrm{W} 1100 \times 400 \times 343 \\
(\mathrm{~W} 44 \times 230)\end{array}$ & $\begin{array}{c}\text { W } 360 \times 410 \times 509 \\
(\mathrm{~W} 14 \times 342)\end{array}$ & None & $\begin{array}{l}a=201 \\
b=709 \\
c=68.3\end{array}$ \\
\hline SP3 & $\begin{array}{c}\text { W } 920 \times 420 \times 1377 \\
(\text { W } 36 \times 925)\end{array}$ & $\begin{array}{c}\text { W } 360 \times 410 \times 1299 \\
(W 14 \times 873)\end{array}$ & $32 \mathrm{~mm}$ & $\begin{array}{l}a=236 \\
b=710 \\
c=99.3\end{array}$ \\
\hline SP4 & $\begin{array}{c}\text { W } 1100 \times 400 \times 607 \\
(\mathrm{~W} 44 \times 408)\end{array}$ & $\begin{array}{c}\text { W } 1000 \times 400 \times 748 \\
(W 40 \times 503)\end{array}$ & None & $\begin{array}{l}a=304 \\
b=950 \\
c=85.3\end{array}$ \\
\hline
\end{tabular}

Table 2 - Slenderness parameters

\begin{tabular}{|c|c|c|c|c|c|c|}
\hline \multicolumn{2}{|c|}{ Section } & $\begin{array}{c}\mathrm{b}_{\mathrm{f}} \\
\mathrm{mm}\end{array}$ & $\begin{array}{c}\mathrm{t}_{\mathrm{f}} \\
\mathrm{mm}\end{array}$ & $\begin{array}{c}\mathrm{h} \\
\mathrm{mm}\end{array}$ & $\mathrm{h} / \mathrm{t}_{\mathrm{w}}$ & $\mathrm{b}_{\mathrm{f}} / 2 \mathrm{t}_{\mathrm{f}}$ \\
\hline W $14 \times 16 \times 342$ & W $360 \times 410 \times 509$ & 416 & 62.7 & 320 & 8.2 & 3.3 \\
\hline W $14 \times 16 \times 873$ & W $360 \times 410 \times 1299$ & 476 & 140 & 320 & 3.2 & 1.7 \\
\hline W $36 \times 16.5 \times 652$ & W 920 x 420 x 970 & 446 & 89.9 & 863 & 17.3 & 2.5 \\
\hline W $36 \times 16.5 \times 925$ & W $920 \times 420 \times 1377$ & 473 & 115.1 & 863 & 11.3 & 2.1 \\
\hline W $40 \times 16 \times 503$ & W 1000 x 400 x 748 & 417 & 70 & 928 & 23.8 & 3.0 \\
\hline W $44 \times 16 \times 230$ & W 1100 x $400 \times 343$ & 400 & 31 & 1028 & 57.1 & 6.5 \\
\hline W $44 \times 16 \times 408$ & W 1100 x 400 x 607 & 410 & 55 & 1028 & 33.2 & 3.7 \\
\hline
\end{tabular}

Table 3 - Displacemnt load history

\begin{tabular}{ccc}
\hline Step & $\begin{array}{c}\text { Interstory } \\
\text { Drift Angle } \\
(\%)\end{array}$ & $\begin{array}{c}\text { Number of } \\
\text { Cycles }\end{array}$ \\
\hline 1 & 0.375 & 6 \\
2 & 0.5 & 6 \\
3 & 0.75 & 6 \\
4 & 0.1 & 4 \\
5 & 1.5 & 2 \\
6 & 2 & 2 \\
7 & 3 & 2 \\
8 & 4 & 2 \\
\hline
\end{tabular}


The behavior of the four specimens can be separated into two types of performance. The smaller specimens, SP2 and SP4, failed by flexural yielding and inelastic local buckling, and achieved the desired deformation capacity, as shown for SP4 in Figure 3. The figure shows the typical softening associated with local buckling after the maximum strength was obtained at $3 \%$ drifts (about 6 in. or $150 \mathrm{~mm}$ of interstory drift).

Specimens SP1 and SP3, the heavier ones, reached flexural yielding, exhibited large overstrength and failed shortly before (SP3) and shortly after (SP1) reaching the desired interstory drift due to weld fracture (see Figure 4 for SP1). As shown in Figure 4, up to the sudden failure there had not been any evidence of softening and the failure occurred with no warning. Moreover, significant hardening was still occurring.

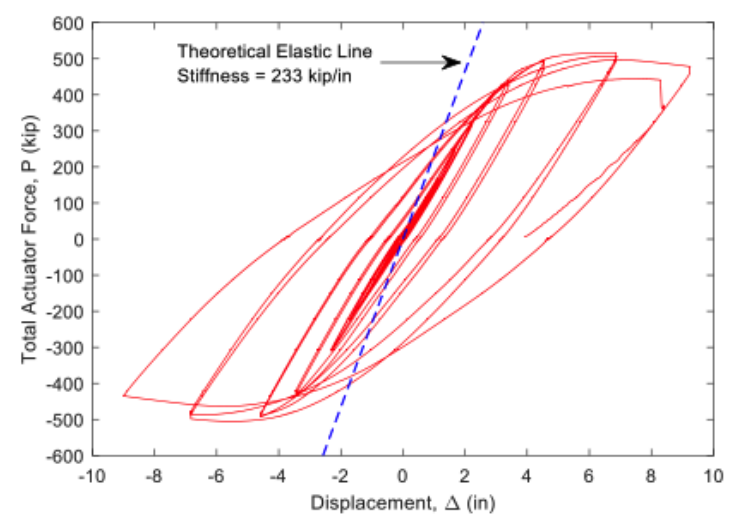

Fig. 3. Behavior of SP4

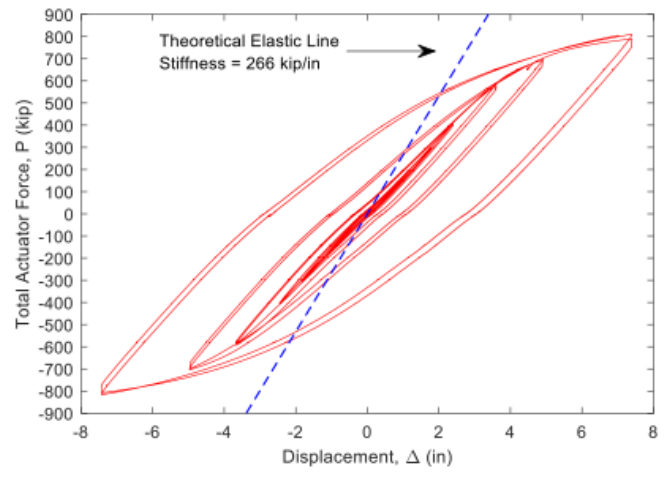

Fig. 4. Behavior of SP1

The unexpected behavior in SP1 and SP3 was attributed to the extreme demands on the very thick welds, for which the conventional design procedures may substantially underestimate the local strain demands under cyclic displacements.

\section{Analytical Studies}

As noted earlier, some FE studies had been conducted prior to the testing both to predict specimen behavior and to assess the forces that the test setup had to be designed for. Initially ABAQUS FE models based on shell elements were used for these purposes; however, it became evident that the panel zone deformations based on this element type would considerably overestimate shear deformation in this area as compared to a model based on solid elements. Therefore, 3D ABAQUS models based on solid elements such as those shown in Figure 5 were used throughout the rest of the studies. These initial studies indicated far more shear panel zone yielding than assumed from simple models.

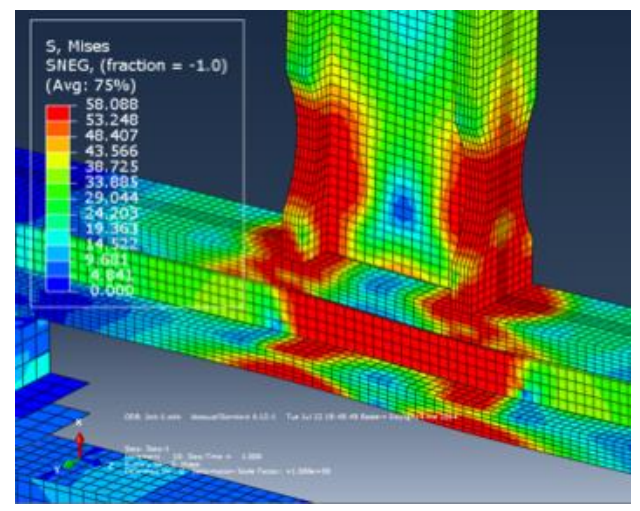

Fig. 5. Initial ABAQUS 3D models

These models were also used to conduct additional studies on the effect of doubler plates, which were needed in SP3 to control the large predicted yielding in the panel zone, as shown in Figure 6.

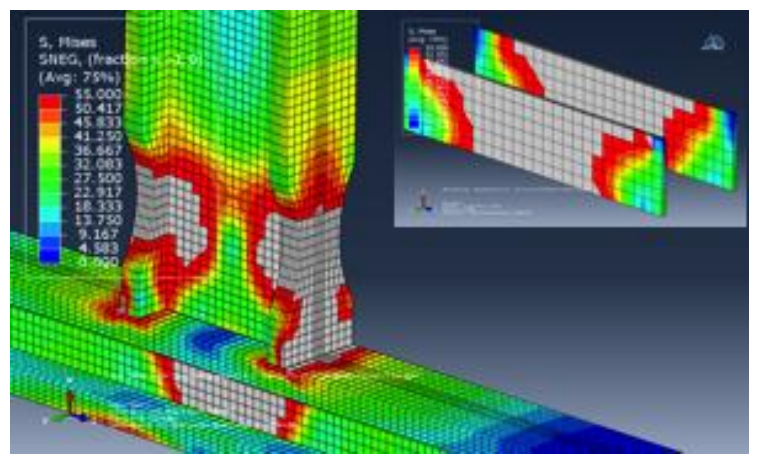

Fig. 6. Effect of doubler plates

Much more refined 3D FE models were used in the more recent simulation efforts. For these models, the approximate mesh size was only $13 \mathrm{~mm}$ in the connection area, while a $50 \mathrm{~mm}$ element size was used in the rest for the model as shown in Figure 7. Eight-node solid elements 
were employed in most parts of the models, except in the transition zone between the $13 \mathrm{~mm}$ and $50 \mathrm{~mm}$ elements where ten-node quadratic tetrahedron elements were used. All welds were explicitly modeled.

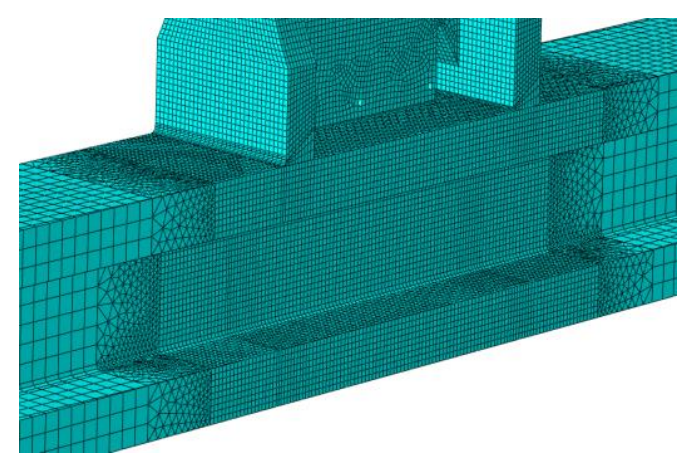

Fig. 7. Refined mesh

The more recent simulations were meant to track the cyclic behavior and thus advanced material models were adopted. To better track the material behavior, the steel cyclic nonlinear constitutive model in these analyses was patterned after the multiaxial formulations by Armstrong and Frederick (A-F model) which integrate the material model with hardening rules [6]. The hardening rules contain two parts, an isotropic and a kinematic hardening part. The isotropic part is defined by the size of the yield surface, which results in an uniform expansion and constant growth of the surface at every cycle. The kinematic hardening part is defined as a shift of the yield surface in 3D principal stress space and controlled by the basic Ziegler law [6]. The values for material models were based on material tests.

To properly track the local buckling initial imperfections corresponding to an amplitude of $1 / 500$ of the beam depth with a shape derived from a summation of the first two modes were used. In addition, careful attention was taken to properly model the residual stresses particular to very thick sections [7] as shown in Figure 8.

This paper will focus on the analytical studies of SP2 and SP4, which are well understood. Studies are ongoing on SP1 and SP3 and will be reported in future publications.

\section{Simulation Results}

Initial comparisons were made to the deformed shapes, as shown in Figure 8. These comparisons indicated that the models were capable of tracking the behavior well into the inelastic range. The model proved capable of tracking the initiation and development of both local buckling in the beam and panel zone yielding in the column. The very high stresses shown in the scale to Figure 11 are very local stresses in the weld.

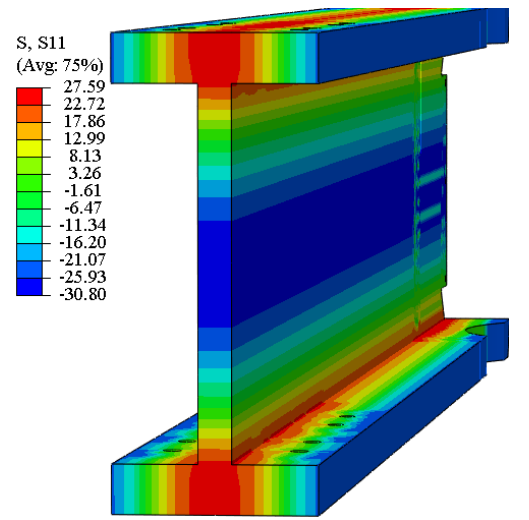

Fig. 8. Residual stresses (W920x420x1377 section)
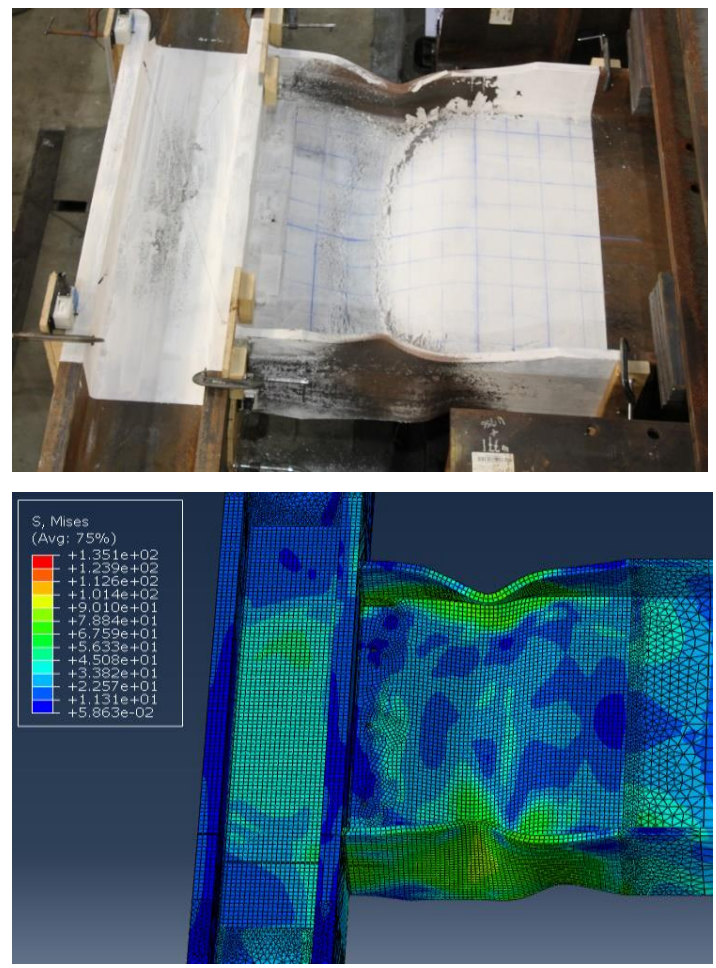

Fig. 9. Comparison of actual and computed deformations for SP2 at 3\% drift

Comparisons of the hysteretic curves, as shown in Fig. 10 for SP2, indicate that the models properly tracked the onset and magnitude of the local buckling for the lighter specimens. 


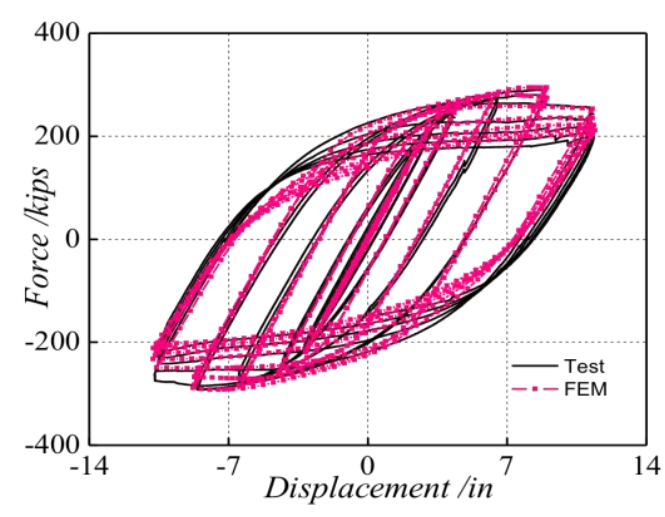

Fig. 10. Comparison of hysteretic curves from test and models for SP2

The very fine mesh around the critical areas allowed careful study of the distribution of strains in the weld areas. The design of the RBS assumes a very simple model in which plane sections are assumed to remain plane and thus the stress distribution through the beam flange depth is assumed as linear. However, this assumption is widely different from the FEM results (Figure 11). Figure 11 shows contours of the principal stress S11 for SP2 and SP4. The values shown indicate that the stresses are smaller on the inside portion of the beam flange, while the stresses on the outside potion actually exceed the true ultimate strength.

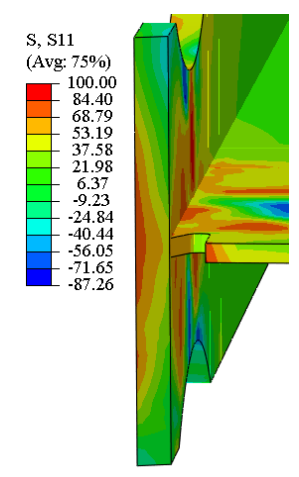

(a) $\mathrm{SP} 2$

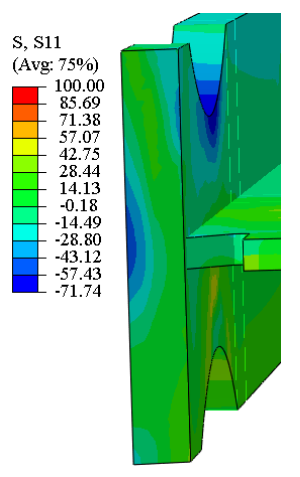

(b) SP4
Fig. 11. S11 stress contours for the different beams

\section{Conclusions}

The advanced models described here have led to the following preliminary conclusions:

1. The behavior of the specimens shows that SP2 and SP4 failed by flexural yielding and inelastic local buckling.

2. The analytical results are in good agreement with the experimental observations and measured behavior. The balance between the amount of flexural hinging in the RBS region and the shear deformation of the column panel is affected by both the geometry of the connection and the material properties. Further parametric studies in this area are needed to determine whether a proper balance can be obtained in the initial design between these two-deformation mechanisms based on nominal material properties, and the RBS can be viewed as a ductile seismic fuse in the loading.

3. The distribution of principal stresses S11 are smaller on the inside part of the beam flange, and much larger on the outside, particularly as the beam flange thickness increases. The assumption made in design that the stresses in this area are uniform needs to be reevaluated.

\section{Acknowledgements}

These studies were made possible by a grant from the National Scholarship Council of China to Mr. Qi and by the generosity of the Advanced Research Computing Center at Virginia Tech.

\section{References}

[1] Plumier A. New idea for safe structures in seismic zones. IABSE Symposium: Mixed structures including new materials-Brussels, 1990. p. 431-6.

[2] SAC Joint Venture. State of the art report on systems performance of steel moment frames subject to earthquake ground shaking. FEMA 355C. 2000.

[3] AISC Specification for Structural Steel Buildings, ANSI 360-16, AISC, 2016, Chicago, IL

[4] AISC. Seismic Provisions for Structural Steel Buildings, ANSI 341-16, AISC, 2016, Chicago, IL

[5] AISC. Prequalified Connections for Special and Intermediate Steel Moment Frames for Seismic Applications, ANSI 358-14, AISC, 2014, Chicago, IL

[6] Armstrong P. A mathematical representation of the multiaxial Bauschinger effect. CEBG Report RD/B/N, 731. 1966.

[7] Spoorenberg R, Snijder H, Cajot L-G, May $M$. Experimental investigation on residual stresses in heavy wide flange QST steel sections. Journal of Constructional Steel Research. 2013;89: 63-7 